$\xi=-1$

\title{
Termination of Pregnancy by Rape Victim: the Dilemma in Malaysian Criminal Law
}

\author{
Ramalinggam Rajamanickam $^{1 *}$, Teh Kok Ann ${ }^{1}$, Tengku Noor Azira Tengku Zainudin ${ }^{1}$, \\ Ahmad Azam Mohd Shariff ${ }^{1}$ \\ ${ }^{1}$ Faculty of Law, Universiti Kebangsaan Malaysia \\ *Corresponding author E-mail: rama@ukm.edu.my
}

\begin{abstract}
Abortion is a complex issue as people have different views and reasons to terminate a pregnancy. The act of abortion does not only involves adults but also young girls. Generally, abortion is an offence punishable under the Penal Code of Malaysia. However, the issue of abortion becomes crucial when the abortion involves the victim of rape. The contending issue is to what extent does the Malaysian Penal Code legally allow the victim of rape to undergo an abortion. The provision that allows abortion is ambiguous in this context. Therefore, this article intends to analyse the legal position relating to abortion by rape victims in the Malaysian Penal Code. This article also serves to compare the position of abortion by victim of rape in India and Singapore. The article finds that the exception to the general principle on abortion in the Malaysian Penal Code is inadequate in protecting rape victims as compared to India and Singapore. Hence, it is urged that Malaysia should revise the law on abortion relating to victim of rape. However, some challenges have been identified before the country can amend the law.
\end{abstract}

Keywords: Abortion; Rape Victim; Penal Code; Malaysia.

\section{Introduction}

Abortion is a moral, jurisprudential and criminal issue which has been debated by jurists for decades without conclusion. An abortion could be resulted from series of events, deliberate or otherwise, which eventually and finally end up with the woman becoming pregnant and going for abortion to conceal matters out of guilt and shame. Such a scenario is no longer a rarity in our society due to some women deliberately participating in sexual activities outside marriage. On the other hand, the growing number of abortion cases in any society may possibly be associated also to the sexual harassment factor. Over the years, more and more women across the globe have become victims, suffering in silence as some of these unwanted sexual advances begin to escalate to actual indulgence in actual sexual activities which eventually resulting in rape $[1,2]$.

Indeed, some countries have started to propose and even implemented a more humanized legislative on abortion to suit the need of the society. Unlike other commonwealth countries like United Kingdom, India and Singapore, there is no specific Act that governs abortion in Malaysia. The act of abortion is still governed by the Penal Code alone without any further amendment after 1989. The issue of abortion becomes more vital when it involves the abortion by rape victims as the statistics showed that the incidence of rape cases is becoming more serious. However, as have been mentioned above, currently the Malaysian legislative does not have any specific Act to regulate this practice.

\section{General Principle on Abortion in Malaysia}

Generally, abortion is governed by Section 312 to Section 316 of the Penal Code. Section 312 of the Penal Code is the main provision to be referred to in cases involving abortion. Section 312 of the Penal Code provides:

"Whoever voluntarily causes a woman with child to miscarry shall be punished with imprisonment for a term which may extend to three years, or with fine, or with both; and if the woman be quick with child, shall be punished with imprisonment for a term which may extend to seven years, and shall also be liable to fine."

Explanation- A woman who causes herself to miscarry is within the meaning of this section.

According to this Section, causing a woman with child to miscarry is an offence under the penal law. The provision consists of two limbs. First limb deals with causing a woman with child to miscarry, and second limb dealt with causing woman quick with child to miscarry. The difference between the two limbs is the punishment. An offence that falls under the first limb is punishable with a maximum of 3 years' imprisonment, or fine, or both. An offence that falls under the second limb will invite a heavier punishment, that is, a maximum of 7 years' imprisonment, or fine, or both.

Based on the case of Public Prosecutor v. Dr Nadason Kanagalingam [1985] 2 MLJ 122, to convict a person under (first limb of) Section 312 of the Penal Code, the Prosecution needs to prove beyond reasonable doubt that:

i. The woman who was caused to miscarry was pregnant;

ii. The accused voluntarily caused her to miscarry; and 
iii.

Such miscarriage was not caused by the accused in good faith for the purpose of saving the life of the woman.

The interesting part of this provision is that this provision does not deal with the element of consent from the pregnant woman. The arising issue here is whether such consent of a pregnant woman can stand as a valid defence for the accused who voluntarily caused the pregnant woman to miscarry? By referring to Section 91 of the Penal Code, it is stated that the exceptions under Section 87,88 and 89 do not extend to the acts which are offences independently of any harm. Illustration of Section 91 clearly stated that the general defences of free consent under Section 87, 88 and 89 are not applicable to the offence under Section 312 as Section 312 is an offence independently of any harm. Therefore, even though the one who causes the pregnant woman to miscarry obtained prior consent from the woman, or her guardian, it does not justify the act of causing her miscarriage.

The explanation of Section 312 of the Penal Code further extends the offence to a woman who voluntarily causes herself to miscarry. Consequentially, if a woman voluntarily causes herself to miscarry, she can be convicted under Section 312. The case of Empress v Ademma (1886) ILR 9 Mad 369 illustrates this situation clearly. In this case, the accused had been charged because she voluntarily caused herself to miscarry. At the stage of the subordinate court, the accused was acquitted because she was only one month pregnant, and hence does not fall within the definition of "woman with child." However, at the High Court, the court set aside the judgment from the subordinate court and ordered for a retrial because the court was of the opinion that it is sufficient to prove the woman's pregnancy, hence rendering the pregnancy term unimportant. The significance of this case is that, it affirms the legal position that, no matter how far the pregnancy is, be it only one week, no one can cause the woman to miscarry including the woman herself.

It is important to note that the Penal Code imposes a more serious punishment when a person causes a woman quick with child to miscarry under the second limb of Section 312 of the Penal Code. The element of the offence punishable under this limb is similar to that of the first limb. The only difference is that in second limb, the woman who was caused to miscarry was not only required to be pregnant, but also be quick with child. According to Ratanlal, a woman is said to be quick with child when she experiences sensation from the child around the fourth to the fifth months of the pregnancy [3]. In the case of Goldsmith 3 Camp76 quick with child refers to any time when the pregnant woman feels the move within her. Hence, to convict an accused under the second limb of Section 312 , the prosecution needs to prove, first and foremost, that the woman felt the movement within her.

From the discussion above, we may conclude that generally abortion is an offence in Malaysia regardless of the consent obtained from the woman and the period of the pregnancy. Even in situations where the woman is not pregnant but the accused had at tempted to cause her miscarriage, it is still an offence punishable under Section 511 of the Penal Code as decided in the case of Munah Binti Ali v Public Prosecutor [1958] 1 MLJ 159.

\section{Exception to the General Rule: Does a Vic- tim of Rape Falls under the Exception?}

Although Section 312 of the Penal Code clearly prohibits abortion, the exception of Section 312, however, allows abortion in certain situations. Exception of Section 312 states:

"This Section does not extend to a medical practitioner registered under the Medical Act 1971 [Act 50] who terminates the pregnancy of a woman if such medical practitioner is of the opinion, formed in good faith, that the continuance of the pregnancy would involve risk to the life of the pregnant woman, or injury to the mental or physical health of the pregnant woman, greater than if the pregnancy were terminated."
According to this exception, abortion is legal provided that:

i. The abortion was done by a medical practitioner registered under Medical Act 1971.

ii. The abortion can only be performed when the medical practitioner is of the opinion, formed in good faith that the continuance of the pregnancy would involve risk to the pregnant woman, greater than if the pregnancy were terminated.

iii. The risk stated must be risk to the life of the pregnant woman, or injury to the mental or physical health of the pregnant woman.

The first requirement is clear and undisputed that only medical practitioner registered under Medical Act 1971 can carry out the abortion. There are significantly two main issues to be determined here. First of all, what is meant by good faith? Secondly, how would a medical practitioner determine that the risk is greater for a pregnant woman if she continues with her pregnancy than if the pregnancy is terminated?

First and foremost, what amounts to good faith? Section 52 of the Penal Code states that "nothing is said to be done or believed in good faith which is done or believed without due care and attention." The gist of this provision indicates that one is only said to have good faith when he did the act with due care and attention as required by law. From the cases R v Bourne [1938] All ER 615 and Public Prosecutor v Dr Nadason Kanagalingam [1985] 2 MLJ 122 , the burden of prove to show that the abortion is not done in good faith falls on the prosecution.

In $\mathrm{R} v$ Bourne, a highly skilled surgeon performed an abortion by operation, without any charge on a 15 years old girl who got pregnant due to rape. In this case, the expert witness evidence showed that the effect to the mental of the girl produced by her pregnancy caused by the rape is very serious. In this case, Macnaghten J. when delivering judgment, although he did not mention the phrase "good faith," gave an example of the meaning by stating that:

"...and I mention that case only to show you how different the case now before you is from the type of case which usually comes before a criminal court. In that case, a women without any medical skill or any medical qualification did what is alleged against $\mathrm{Mr}$. Bourne here: she unlawfully used an instrument for the purpose of procuring the miscarriage of a pregnant girl. She did it for moeny. $£ 2.5 \mathrm{~s}$. was her fee, and she came from a distance to a place in London to do it. $£ 1$ had to be paid to make the appointment. She came, she used her instrument, and, within an interval of time measured not by minutes but by seconds, the victim of her malpractice was dead on the floor. She was paid the rest of her fee and she went away. That is the class of case that usually comes before the court. The case here is very different. A man of the highest skill, openly, in one of our great hospital, performs the operation. Whether it was legal or illegal you will have to determine, but he performs the operation as an act of charity, without fee or reward, and unquestionably believing that he was doing the right thing, and that he ought, in the performance of his duty as a member of a profession devoted to the alleviation of human suffering, to do it."

The above observation from the judge clearly indicates that although the court did not mention the phrase "good faith," the court nevertheless was trying to distinguish between "with good faith" and "without good faith". According to the judgment, a person is said to perform the operation without good faith, when he, without skill on abortion, and without carrying out any further examination, aborts the child in just a few seconds. In such scenario, he is deemed to have failed to exercise reasonable care expected of a doctor carrying out an abortion. Besides, a doctor is said not to be in good faith when his/her intention is to obtain profit and not because of his/her belief that the abortion is a good choice for the patient. On the other hand, the court held that in $\mathrm{R} v$ Bourne, $\mathrm{Mr}$ 
Bourne, the accused was acting in good faith as he highly skilled and performed the operation with the pure intention of preserving the life of the girl.

A different decision was reached by the judge in Public Prosecutor v Dr. Nadason Kanagalingam where it was held that the accused was liable under Section 312 because he did not act in good faith to preserve the mother's life. In this case, the accused performed an operation to abort the pregnant woman on the basis that the pregnant woman suffered from bad or enlarged varicose veins which may cause pulmonary embolism that can be fatal to the pregnant woman. The expert evidence further showed statistics that in the United Kingdom, 27.5 out of every 10,000 pregnancies died due to pulmonary embolism. However, there is no statistic to show how many percent of these 27.5 cases of pulmonary embolism are caused by enlargement of varicose veins. According to the court, procuring abortion is a very serious matter and it should only be done as a last resort to save the life of a woman or to save a woman from becoming a mental wreck. The court was of the opinion that no reasonable doubt has been raised regarding the accused not taking enough steps to examine the pregnant woman further but depending solely on clinical examination.

By referring to both cases, a medical practitioner is said to have acted in good faith when he has given enough reasonable consideration before aborting the child. The medical practitioner should examine the pregnant woman further to identify the risk involved instead of just depending on mere clinical examination.

Moving on to the next issue of how determination of risk during pregnancy term is made in satisfaction of the Exception under section 312 of the Penal Code. In other words, how would a medical practitioner determine that the risk is greater for a pregnant woman if she continues with her pregnancy than if the pregnancy is terminated? This is the third and last requirement for a woman to undergo an abortion. However, the Penal Code does not define what amounts to "greater risk." In the case of Attorney General of Ireland v X [1992] 1 IR 1, a 14 years old girl was found to be pregnant after being raped by her father's friend. Therefore, the parent decided to bring her to England to abort the child. However, the Attorney General applied and was granted an interim injunction from the High Court to restrain them to leave Irish for 9 months. However, the Ireland Supreme Court nullified the injunction and held that the girl could undergo abortion. This is because the court was of the opinion that there was a substantial risk to the life of the girl because the girl has the risk to commit suicide and the risk can only be prevented by having an abortion. This situation was similar to the case of $\mathrm{R} v$ Bourne, where the court did not convict the accused because the court was satisfied that continuing the pregnancy would cause a serious mental injury to the pregnant girl and furthermore, the pelvic bones of a 15 year-old girl is not suitable for pregnancy. Whereas in the case of Dr Nadason Kanagalingam, the court held that the accused was guilty because there was no evidence to support that the risks involved was serious.

Based on the discussion above, we may conclude that abortion can be done when the three elements are fulfilled. However, the courts in those cases did not lay down any guideline to measure the degree of the risks to the life and health that must be faced by the pregnant woman to enable her to have an abortion. Hence, when it comes to the issue of abortion by a victim of rape, the question is whether the exception of Section 312 of the Penal Code is wide enough to protect the victims of rape?

In the Penal Code, there is no specific provision to allow a rape victim to undergo an abortion. When deciding whether to perform an abortion for victims of rape, the medical practitioner can only depend on the reasoning that continuance of pregnancy involves risk to the life of the pregnant woman or injury to the mental or physical health of the pregnant woman, and such risk is greater than that of if the pregnancy were terminated. Although the court in the case of $\mathrm{R} v$ Bourne held that abortion by rape victims is allowed, the ratio of the judgment is not because the pregnant woman was victims, but because continuance of pregnancy will cause injury to the physical and mental of a 15 years old girl. Therefore, there is an ambiguity here when section 312 fails to define what would amount to physical and mental injury. There is also no decided cases in Malaysia that can be referred to pertaining to the question of the extent of physical and mental injury in consideration in allowing a rape victim to legally abort a child.

Therefore, the absence of the definition of physical and mental injury in section 312 causes ambiguity in deciding whether a victim of rape who undergoes abortion falls under the exception of section 312 Penal Code.

\section{Position of Abortion by Victim of Rape in other Jurisdictions}

\subsection{India}

The abortion in India is governed by the Indian Penal Code and Medical Termination of Pregnancy Act 1971 (MTPA) [4]. The provisions of the Indian Penal Code which governed abortion are very similar to the corresponding provisions under sections 312 until 316 of the Malaysian Penal Code with section 312 being the main provision on abortion. Section 312 of Indian Penal Code provides that:

"Whoever voluntarily causes a woman with child to miscarry, shall, if such miscarriage be not caused in good faith for the purpose of saving the life of the woman, be punished with imprisonment of either description for a term which may extend to three years, or with fine, or with both; and if the woman be quick with child, shall be punished with imprisonment of either description for a term which may extend to seven years', and shall also be liable to fine."

Besides adding the phrase if such miscarriage be not caused in good faith for the purpose of saving the life of the woman, this provision is almost pari materia with section 312 of the Malaysian Penal Code. According to this provision, abortion can only be performed to preserve the pregnant woman's life. This means that the section is stricter compared to section 312 of Penal Code Malaysia.

However, the Medical Termination of Pregnancy Act 1971 (MTPA) has been introduced to justify some of the abortion. According to MTPA, it is not an offence if the pregnancy has been terminated by a medical practitioner accordance with MTPA. According to Section 3(2) MTPA pregnancy can be terminated by a registered medical practitioner if the pregnancy is not more than 12 weeks and the medical practitioner is of the opinion, formed in good faith that:

(i) the continuance of the pregnancy would involve a risk to the life of the pregnant woman or of grave injury physical or mental health; or ${ }^{6}$

there is a substantial risk that if the child were born, it would suffer from such physical or mental abnormalities as to be seriously handicapped ${ }^{7}$

Under Section 3(2) of MTPA, there are two important explanation:

Explanation 1.-Where any, pregnancy is alleged by the pregnant woman to have been caused by rape, the anguish caused by such pregnancy shall be presumed to constitute a grave injury to the mental health of the pregnant woman.

Explanation 2.-Where any pregnancy occurs as a result of failure of any device or method used by any married woman or her husband for the purpose of limiting the number of children, the anguish caused by such unwanted pregnancy may be presumed to constitute a grave injury to the mental health of the pregnant woman. 
Explanation 1 makes a very important presumption. It presumes that if the pregnancy is alleged by the pregnant woman to have been caused by rape, it constitutes a grave injury to the mental health of the pregnant woman and therefore abortion is not an offence under Section 3(2)(i) of the MTPA [5]. Hence, we can say that the law of abortion in India gives the victim of rape enough protection regarding abortion by acknowledging their will to continue or terminate the pregnancy when the pregnancy comes from an unwanted incident.

However, the technical issue that arises is how to prove that the woman gets pregnant due to rape? The general legal principle is that one is not guilty until it is proven. Therefore, can a woman claims that the pregnancy occurs due to rape without proving it? If the accused can be tracked, should the abortion be put on hold until the guilt of rape has been proven? And if the accused cannot be tracked, what is the mechanism available for the court in helping it to decide whether or not the woman who requested to have the abortion is lying?

From here we can see that even where the law itself gives protection to the pregnant woman, there are still many legal issues to be resolved. The reform of the law of abortion involves not only on the law of crime, but also the law of evidence and the law of criminal procedure.

\subsection{Singapore}

In Singapore, Section 312 of Singapore Penal Code which governs abortion provides:

Subject to the provisions of the Termination of Pregnancy Act (Cap. 324), whoever voluntarily causes a woman with child to miscarry, shall be punished with imprisonment for a term which may extend to 3 years, or with fine, or with both; and if the woman is quick with child, shall be punished with imprisonment for a term which may extend to 7 years, and shall also be liable to fine. Section 312 of the Singapore Penal Code differs from Section 312 of the Malaysian Penal Code in that, Section 312 of the Singapore Penal Code is subject to the Termination of Pregnancy Act 1974 (TPA). Section 3(1) of TPA provides that "no person shall be guilty of an offence under the law relating to abortion when the pregnancy is terminated by an authorised medical practitioner acting on the request of a pregnant woman and with her written consent."

Literally, Section 3(1) of TPA indicates that if a woman needs to undergo an abortion, regardless of whether the pregnancy was due to rape, or any other reasons, it is permissible under the law if (i) the pregnancy is terminated by an authorised medical practitioner (ii) the abortion is on request of a pregnant woman and (iii) the pregnant woman must give written consent. Although the law seems liberal, there are still some limitation on it. The abortion is illegal if the pregnancy is more than 24 weeks, unless the abortion is immediately necessary to save the life or to prevent grave permanent injury to the physical or mental health of the pregnant woman. ${ }^{8}$

Although the limitations are there, the law of abortion in Singapore is still liberal when compared to Malaysia. However, not al women can "enjoy" the right to abort in Singapore. Section 4(1)(a) TPA [6] states that abortion is only applicable to the woman who is: ${ }^{9}$

i. a citizen of Singapore or is the wife of a citizen of Singapore;

ii. a holder, or is the wife of a holder of a work pass issued under Singapore Employment Foreign Manpower Act; or

iii.

resident in Singapore for a period of at least 4 months immediately preceding the date on which abortion is to be carried out.

The implication of Section 4(1)(a) the TPA is that, the authorised medical practitioner is not allowed to perform abortion on a Ma- laysia citizen even if she is a rape victim because of her ineligibility in the eyes of the law.

However, with regards to the issue on whether the victim of rape gets enough protection to undergo abortion in Singapore, the answer is definitely positive as Singapore allows all kinds of abortion regardless the reasons of the abortion as long as the requirements in the statute are fulfilled.

\section{Conclusion}

The above legal arguments and analysis has led us to a conclusion that the approach of the criminal law in Malaysia on the issue of abortion is different from other jurisdictions. Abortion is an offence under the Malaysian criminal law. Although the exception provides for some justifications to undergo abortion, the exception does not spell out clearly whether the victims of rape can undergo abortion. This is remarkably different from the positions in India and Singapore which permit abortion to be performed for the victims of rape. The laws in Singapore and India literally spelled out that the victims of rape can undergo abortion if the abortion is requested by them willingly.

In this context, it is urged that the position of criminal law in Malaysia on abortion be re-evaluated to determine whether there is a need for the Parliament to permit rape victims to undergo abortion to protect the rights of the victims as well as the benefit of society.This is important especially when the statutory rape becomes more and more serious in the Malaysian society and it leads to unsafe abortion or even abandonment of new born child. Therefore, a pregnant rape victim should be permitted by law to undergo abortion by taking into account the psychological problems and the mental trauma involved.

However, the main challenge faced is: when can a rape victim undergo the abortion? Does the rape victim need to wait for the judgment from the court after full trial on the rape issue before she can undergo the abortion? If that is the case, then the rape victim will need to wait for a very long time and it is not impossible that by the time the trial ends, she might have already delivered the child. On the other hand, if the rape victim does not need to get prior order from court, abortion might be carried out without control. Any woman can come to a medical practitioner and claims that she had been raped and request for an abortion without any proof. Therefore, when re-evaluating the law of abortion, all of these technical issues should be taken into consideration.

\section{References}

[1] Rohani Abdul Rahim (2008), Fenomena Gangguan Seksual Terhadap Pekerja Wanita Dalam Organisasi: Suatu Implikasi Dalam Perundangan Malaysia, 12 Jurnal Undang-undang dan Masyarakat, UKM: Penerbit UKM, 145-148

[2] Farley L (1978), Sexual Shakedown: The Sexual Harassment of Women On The Job, New York: McGraw-Hill

[3] Ratanlal \& Dhirajlal (2010), Ratanlal \& Dhirajlal's: The Indian Penal Code, 32th Edition, Wadhwa Nagpur, India : LexisNeis Butterworth, 1795 .

[4] Medical Termination of Pregnancy Act (1971).

[5] Section 3(2)(i) Medical Termination of Pregnancy Act (1971)

[6] Section 4(1)(a) Termination of Pregnancy Act (1974). 